\title{
Л.Н. Смолякова
}

\section{БЕЗРАБОТИЦА КАК ПРОБЛЕМА ОБРАЗОВАНИЯ: ВЗГЛЯД АМЕРИКАНСКОГО ЭКОНОМИСТА П.З. ПИЛЗЕРА}

\begin{abstract}
Статья посвящена анализу взглядов американского экономиста П.З. Пилзера на проблемы безработицы США после кризиса 2008-2009 гг. Помимо роста социальных требований к профессиональным качествам рабочей силы в условиях внедрения новых технологий, автор называет другие причины увеличения числа безработных - стагнацию инноваций в США в первое десятилетие XXI в., демонтаж крупных корпораций, а также изменения на «первом рынке труда». Выявленные причины и отличительные признаки современной безработицы позволяют П.З. Пилзеру сделать вывод о становлении новой крупнейшей отрасли в США по переподготовке рабочей силы и сформулировать рекомендации по сокращению числа незанятых на рынке труда. Особый интерес представляет теория исследователя о том, что безработица - это необходимый и позитивный признак того, что экономика растет.

Ключевые слова: США; безработица; П.З. Пилзер; кризис 2008-2009 г.; бизнес-возможность.
\end{abstract}

В своем выступлении в конгрессе США в конце февраля 2017 г. президент Д. Трамп назвал шокирующие цифры, касающиеся проблемы безработицы в стране: 94 млн человек безработных, или 42\% [1]. Подводя итоги своей деятельности на посту президента в ноябре того же года, глава Белого дома с гордостью, в частности, заявил, что безработица в октябре 2017 г. достигла минимума с декабря 2000 г. - 4,1\% [2].

Стоит отметить, что прозвучавшие цифры 42 и 4,1\% невозможно сравнивать между собой, потому что они из разных списков. В США для учета безработицы используют различные индикаторы, которые учитывают совокупность определенных факторов занятости. Популярная цифра, чаще всего представляемая прессой, это число, которое каждый месяц выпускает Бюро статистики труда (BLS) - U-3. U-3 преуменьшает истинную картину безработицы, учитывает людей, которые находятся в активном поиске работы в течение последних четырех недель, и исключает тех, кто не активно ищет работу. Уровень безработицы с учетом американцев, выбравших частичную занятость исключительно по причинам экономического характера (индикатор U$6)^{1}$, составил в октябре 2017 г. 7,9\% (самый низкий показатель с 2006 г.). Фактические показатели безработицы действительно намного хуже тех, которые показал президент во втором заявлении. Существование значительной доли частично безработных является признаком того, что условия на рынке труда неприглядней тех, которые дает официальный уровень безработицы.

Следует признать, что безработица - одна из серьезных проблем, к решению которой ищут подходы президенты постиндустриального периода США, начиная с Дж. Буша-ст. Американский экономист П.З. Пилзер 2 определяет характер современной безработицы как долгосрочный (структурный), решение этой проблемы видит в тесной связке с образованием.

Итак, какова связь современной безработицы в США с проблемами образования? Сначала разберемся с причинами структурной безработицы.
Начнем с глубинных процессов, определяющих развитие американской экономики, - первое десятилетие XXI в. П.З. Пилзер назвал периодом стагнации инноваций [3]. В период с 1999 по 2008 г. ВВП США увеличился на 65\% (с 8,7 до 14,3 трлн долл.). Численность населения за этот же период выросла всего на 10\% - с 273 до 303 млн человек. Это привело, отмечает автор, к увеличению доходов от заработной платы и инвестиций. Однако в сложившихся условиях возможности для реализации растущего потребительского спроса мало изменились. Так, например, средняя цена нового автомобиля в Соединенных Штатах выросла на 40\%, с примерно 20 тыс. долл. в 1999 г. до 28 тыс. долл. в 2008 г., без каких-либо значительных изменений качества или производительности. «Я помню каждый новый автомобиль, который мой отец покупал в 1960-е гг., а также то, чем он превосходил замененный автомобиль, - поясняет П.З. Пилзер. - Кондиционер, автоматическая коробка передач, стеклоподъемник с электроприводом, ремни безопасности - этот список можно продолжать... Или, если вы не приобретали новый автомобиль для новой функции, вы приобретали новый автомобиль, потому что он стоил меньше... В настоящее время не было новых функций, которые могли бы стать веской причиной для покупки нового автомобиля» [3]. Таким образом, считает П.З. Пилзер, в предшествующий кризису 2008-2009 гг. период имело место снижение покупательского спроса, а растущая в это время безработица была вызвана неспособностью многих предприятий сохранить своих клиентов, предоставив им новые или улучшенные продукты и услуги.

Для возвращения интереса клиентов компаниям необходимо предложить новые продукты, которые действительно заслуживают того, чтобы их покупать. Если бы Детройт - «автомобильная столица мира» середины XX в., - утверждает автор, отреагировал на рост цен на нефть до 5 долл. за галлон и предложил энергоэффективные автомобили, то смог бы удовле- 
творить потребительский спрос, а также пережить нагрянувший в 2008 г. кризис ${ }^{3}$.

Кризис 2008-2009 гг. в США вызвал массовые банкротства, охватившие и банковский, и реальный промышленный сектор. «Фактически большая часть безработицы, которую мы испытываем сегодня, на самом деле является постоянным демонтажем многих наших крупных корпораций, поскольку они конкурируют с небольшими компаниями и индивидуальными предпринимателями» [4], - утверждает П.3. Пилзер, ссылаясь на теорию о «трансакционных издержках» ${ }^{4}$ нобелевского лауреата по экономике 1991 г. профессоpa Р. Коуза [5]. Рональд Коуз считал, что в середине $\mathrm{XX}$ в. «транзакционные издержки» лиц, занимающихся бизнесом и не находящихся под одной крышей, были настолько высокими, что превышали их экономический результат, поэтому ранее большие компании были более эффективными. Сегодня с помощью Интернета, компьютеров и недорогой телефонной связи «трансакционные издержки» отдельных лиц бизнеса незначительны, в связи с этим многие крупные организации больше не должны существовать. Таким образом, постоянный демонтаж крупных корпораций США является устойчивым источником безработицы.

П.3. Пилзер выделил некоторые отличительные черты современного безработного [6]: его прежняя работа не существует, потому что заменена новым методом или машиной, либо продукт больше не производится вообще или больше не производится в США; он не имеет специальных навыков, необходимых сегодня работодателям; у него есть проблемы со здоровьем (например, злоупотребление наркотиками или психологические проблемы).

П.З. Пилзер отмечает, что рынок занятости сегодня неэффективен с позиции запроса предпринимателя, который часто знает, как решить возникшие проблемы, но не готов потратить свои собственные средства на обучение рабочей силы. Кроме того, автор описывает еще одну тенденцию современного «первого рынка труда» - рост безработицы среди выпускников колледжей и одновременно появление небольшого количества вакансий с заработной платой в размере от 60 до 120 тыс. долл. на старте для лучших выпускников новых колледжей, являющихся первыми в своем классе, окончивших самые престижные школы, имеющих лучшие летние стажировки в своих резюме. Например, до 2009 г. крупная компания ежегодно нанимала 1000 новых выпускников колледжей, чтобы заполнить позиции начального уровня в сфере продаж и обслуживания клиентов. Сегодня, благодаря Интернету, текстовым сообщениям sms и автоматическим центрам обработки вызовов, этой же компании может потребоваться только 105 новых выпускников колледжей - 100 выпускников для традиционных позиций и 5 лучших, способных разрабатывать системы и писать тексты для веб-сайтов, текстовые программы sms и сценарии для центров обработки вызовов. Хорошие навыки письма и отличные технические навыки выпускников (например, HTML и веб-дизайн) позволяют компаниям сократить издержки и повысить производительность, поэтому в современном технологическом мире лучшие выпускники колледжей стоят в десять раз больше по сравнению со средним студентом, утверждает П.З. Пилзер [7].

На вопрос президента одного из колледжей известному предпринимателю и экономисту: «“Когда вы нанимаете новоиспеченного выпускника колледжа, на что вы обращаете внимание в первую очередь, что вы ищете?” Я ответил: “Способность писать”. Большинство новоиспеченных выпускников колледжа не имеют хороших навыков письма. Хорошее письмо требует ясного и логического мышления, знания грамматики и способности увлекательно излагать свои мысли. Иногда, - отмечает П.3. Пилзер, - во время собеседования с кандидатом на вакансию я прошу ученика сесть за компьютер (не подключенный к Интернету) в соседней комнате и написать 300-600 слов о нашем интервью и очень часто обнаруживаю, что немногие могут написать четкий абзац» [7]. Бывшие студенты просто не знают о своих собственных недостатках. П.З. Пилзер считает, что необходимо разработать стандартизованное письменное тестирование после бакалавриата, которое будет проводиться для всех выпускников. Такой тест позволит работодателям различить квалифицированных кандидатов, учащимся - выявить свои недостатки, а преподавателям - научить тому, что поможет их ученикам. Социальные требования к профессиональному качеству рабочей силы постоянно растут.

Как известно, для борьбы с безработицей Конгресс США традиционно продляет сроки выплат пособий в зависимости от ситуаций в различных штатах. C продлениями на периоды кризисов продолжительность получения пособия составляет обычно от 46 до 79 недель [8]. Хотя эта политика кажется справедливой, на самом деле, отмечает П.З. Пилзер, Конгресс предлагает плохое решение большинству безработных, поскольку они никогда не вернут свою прежнюю работу. По мнению автора, Конгресс должен рассмотреть вопрос о расширении пособий по безработице для того, чтобы потерявшие работу могли иметь возможность пройти программы обязательного обучения и переподготовки. Для получения пособия по безработице на определенный период времени безработный должен обязательно записаться на курсы или стажировки, чтобы обрести новые навыки или улучшить те, которые востребованы сейчас в рамках имеющихся профессий. Когда правительство сделает это, убеждает П.З. Пилзер, целые отрасли появятся, предлагая программы обучения и развития, а работодатели начнут предлагать стажировки, дающие безработным возможность опробовать новые профессии.

Безработица способствует росту кредитной задолженности. В условиях расширения торгового кредитования многие малые предприятия перестали полностью оплачивать своих поставщиков в декабре 2008 г., когда 
их продажи снизились. В результате огромное количество малых предприятий не имели финансовых возможностей для решения растущей дебиторской задолженности. П.З. Пилзер ссылается на проведенный им опрос местных поставщиков и друзей, владеющих малым бизнесом, который позволил обнаружить, что бизнесмены, обычно зарабатывавшие от 100 до 200 тыс. долл. в год, имеют долги от 1 млн долл. по кредитам и не знают, как им решать эту проблему. Конгрессу и правительству необходимо разработать программы спасения для малого бизнеса, так же как программы крупнейшим банкам и автопроизводителям ${ }^{5}$, считает П.3. Пилзер и прогнозирует, что переподготовка рабочих и предложение заранее упакованных бизнесвозможностей тем, кто не может или больше не хочет работать на кого-то другого, скоро станет крупнейшей отраслью в США [8].

В последние несколько десятилетий повышение квалификации профессиональных работников в США отставало от темпов технологического развития. В условиях кризиса 2008-2009 гг. проблема безработицы обострилась и привлекла внимание правительства и общества. Лучший метод повышение квалификации тренинг. Обучение персонала само по себе является огромной отраслью, и Соединенные Штаты еще не полностью использовали свой потенциал. Организацию переподготовки безработных П.З. Пилзер рассматривает как деловую возможность. Когда правительство введет обязательное условие пройти переподготовку для получения пособия по безработице, появятся целые отрасли, предлагающие программы обучения и развития, а работодателям будут интересны стажировки, дающие безработным возможность опробовать новые профессии, заявляет автор [6].

Для ускорения становления новой крупнейшей отрасли в США по переподготовке рабочих - тех, кто не хочет покидать рынок труда, а также по созданию предложений бизнес-возможностей тем, кто не хочет работать на кого-то другого, П.З. Пилзер рекомендует правительству принять следующие меры: субсидировать работодателей для найма тех, кто получает пособия по безработице; субсидировать рабочие места и / или стажировки с «обратным удержанием заработной платы»; ввести обязательную переподготовку: любой человек, получающий пособие по безработице более 90 дней, должен пройти регистрацию в программах обучения и / или стажировки, спонсируемых местными школами или работодателями; тестировать на наркотики: пособия по безработице не должны выплачиваться более 30 дней без обязательного тестирования на наркотики; расширить общественное образование для взрослых, многие из безработных входят в число 60 млн взрослых американцев без диплома о высшем образовании, однако государственные программы не существуют для лиц старше 19 лет; предложить государственные программы спасения для малого бизнеса; разработать и ввести стандартизованное письменное тестирование после бакалавриата [6].

Для борьбы с фрикционной безработицей ${ }^{6}$ П.З. Пилзер предлагает усилить действие правительственных программ помощи местным «центрам занятости», чтобы помочь трудоустроить ищущих работу в короткие сроки. Кроме того, он настаивает на исключении ситуаций, когда тысячи миллионеров получают пособия по безработице: не выплачивать их тем, кто имеет недвижимость стоимостью более 1 млн долл. или доходы от домашнего хозяйства более 100 тыс. долл.

В целом П.З. Пилзер смотрит на безработицу как на показатель экономического развития и инструмент влияния на его процесс. Безработица, считает он, хотя и является болезненной для рабочих, - это необходимый и позитивный признак того, что экономика растет. По сути, она отключает рабочую силу от менее производительных предприятий, чтобы переучивать ее для работы на новых и более продуктивных, - так же, как в $\mathrm{XX}$ в. миллионы рабочих покинули фермы и ушли на заводы, а затем с фабрик переместились на предприятия сферы услуг. Однако процветать будут только определенные люди, отрасли и экономики - те, кто быстрее адаптируется к новым технологиям и новым рынкам, сможет воспользоваться этим ростом. Это связано с тем, указывает П.З. Пилзер, что темпы изменений стали очень быстрыми.

В сегодняшнем мире работа на себя является более безопасным маршрутом, а работа в корпорации стала более рискованной. Современная тенденция к децентрализации крупных фирм и переходу к более мелким предприятиям, «виртуальным корпорациям» и независимым подрядчикам делает индивидуального предпринимателя гораздо более конкурентоспособным, чем крупную корпорацию. Предприниматели станут крупнейшими бенефициарами этого экономического бума. Мы вступаем в эпоху предпринимателя, уверяет П.3. Пилзер. Изменения в технологиях позволили индивидуальным предпринимателям получить преимущество. Домашние предприятия - один из самых быстрорастущих сегментов в американской экономике, и эта тенденция будет продолжаться по мере того, как эра корпорации, начавшаяся почти сто лет назад, будет уступать место эре предпринимателя [9].

\section{ПРИМЕЧАНИЯ}

\footnotetext{
${ }^{1}$ Способ расчета уровня безработицы U6 (Unemployment Rate) учитывает не только находящихся в активном поиске работы в течение последних четырех недель (U3), но и тех, кто в данный момент не ищет работу, и убедившихся в том, что на данный момент их трудоустройство невозможно, а также трудоустроенных на неполный рабочий день.

${ }^{2}$ Пол Зейн Пилзер - финансовый советник в администрации Р. Рейгана, бывший руководитель финансового сектора крупнейшего международного банка Citibank, профессор Нью-Йоркского университета в 1979-2000 гг., написал 11 книг, изданных на 24 языках, и основал шесть компаний.

3 В 2009 г. две компании «дейтройской тройки» General Motors Company и Chrysler объявили о банкротстве. В 2014 г. итальянский концерн Fiat получил полный контроль над Chrysler.
} 
4 «Трансакционные издержки»- издержки функционирования институциональной структуры бизнеса, в том числе расходы на транспортировку, телефон, почту и т.п.

${ }^{5}$ Например, после объявления процедуры банкротства компанией General Motors Company в 2009 г. правительство США предоставило компании около 30 млрд долл., а взамен получило $60 \%$ акций концерна.

${ }^{6}$ Фрикционная безработица связана с поиском работы уже готовыми специалистами с определенным уровнем профессиональной подготовки и квалификации, дополнительная переподготовка не требуется. Основной причиной этого типа безработицы является несовершенство информации (сведений о наличии свободных рабочих мест).

\section{ЛИТЕРАТУРА}

1. Remarks by President Trump in Joint Address to Congress. URL: https://www.whitehouse.gov/briefings-statements/remarks-president-trump-jointaddress-congress/

2. Безработица в США в октябре опустилась до минимума за 16 лет. URL: http://www.interfax.ru/business/586090

3. The Great Crash of 2008-2009 - What Really Happened? URL: http://www.paulzanepilzer.com/the-great-crash-of-2008-2009-what-really-happened

4. Theory of Nobel Prizewinning Economist Predicts Entrepreneurship vs Employment. URL: http://www.paulzanepilzer.com/ entrepreneurship_vs_employment

5. Ron Coase, 1910-2013. URL: http://www.paulzanepilzer.com/ron-coase

6. Unemployment is Not an Economic Problem-It's an Education Problem. URL: http://www.paulzanepilzer.com/unemployment-is-not-an-economicproblem-its-an-education-problem

7. The Class of 2010 - What New Job Applicants Need Most. URL: http://www.paulzanepilzer.com/the-class-of-2010-what-new-job-applicants-need-most

8. Employment Update: Why Things are About to Get Much Worse. URL: http://www.paulzanepilzer.com/employment-update-why-things-are-about-toget-much-worse

9. Crisis or Opportunity - Your Business Magazine - July 2006. URL: http://www.paulzanepilzer.com/ybcyberwize-htm

Smolyakova Lyudmila N. National Research Tomsk State University (Tomsk, Russian Federation). E-mail: smol_ln@mail.ru UNEMPLOYMENT AS A PROBLEM OF EDUCATION: A VIEW OF THE AMERICAN ECONOMIST P.Z. PILZER

Key words: USA; unemployment; P.Z. Pilzer; crisis 2008-2009; business opportunity.

The rapid growth of unemployment in the United States started after the Great Crash of 2008-2009. The authoritative American economist P.Z. Pilzer in several published articles reflected his view of the nature of the modern unemployment, defining it as a long-term and also explained why he sees the solution to this problem in close conjunction with the educational system. Among the causes of rising unemployment, the author calls not only changing social requirements for the competencies of the workforce due to technology, but also took place in the United States in innovation stagnation in the first decade of the $21^{\text {st }}$ century as well as the dismantling of large corporations and changes on the "first job market".

No significant changes in product quality and productivity in 1999-2008 allow P.Z. Pilzer call this period of stagnation of innovation. Growing at this time, unemployment was caused by the inability of many companies to provide its clients with new or improved products and services and thus save them.

"In fact, a large portion of unemployment that we experience today, is actually a permanent dismantling of many of our major corporations as they compete with small companies and individual entrepreneurs", - P.Z. Pilzer contends, referring to the theory of the "transaction costs" of the Nobel Memorial Prize in Economics in 1991 Professor Ron Coase. Much of the unemployment today is actually the permanent dismantling of large organizations in favor of smaller entrepreneurial units, said P.Z. Pilzer. Today with the help of the Internet, computers inexpensive telephone communication, the "transaction costs" of individuals in business are insignificant.

The current trend towards decentralization of large firms enables P.Z. Pilzer conclude that we are entering the era of the entrepreneur. Home businesses-one of the fastest growing segments in the U.S. economy, and this trend will continue as the era of corporations that began almost a hundred years ago, will give way to the era of the entrepreneur.

New trends of modern unemployment - its growth on the "first job market" for newly-minted college graduates, and the emergence of a small number of vacancies for graduates at starting salaries from $\$ 60000$ to 120000 . Good writing skills and excellent technical skills of graduates allow companies to reduce costs and increase productivity, therefore they are worth ten times more than the average student, alleges P.Z. Pilzer.

The retraining of the unemployed has the potential to become one of the greatest business opportunities of our time, considers P.Z. Pilzer. When the Government will introduce a mandatory condition of retraining to get unemployment benefits, there will be entire industries, offering training and development programs.

In General, the P.Z. Pilzer looks at unemployment as the indicator of economic development and an instrument of influence on his process. Unemployment, he said, while it is painful for the workers, is a necessary and positive sign that the economy is growing.

\section{REFERENCES}

1. Whitehouse.gov. (2017) Remarks by President Trump in Joint Address to Congress. [Online] Available from:

https://www.whitehouse.gov/briefings-statements/remarks-president-trump-joint-address-congress/.

2. Interfax. (2017) Bezrabotitsa v SSHA v oktyabre opustilas' do minimuma za 16 let [Unemployment in the USA fell to a minimum in 16 years in October]. [Online] Available from: http://www.interfax.ru/business/586090.

3. Pilzer, P. (2009a) The Great Crash of 2008-2009 - What Really Happened? [Online] Available from: http://www.paulzanepilzer.com/the-great-crashof-2008-2009-what-really-happened.

4. Pilzer, P. (2013a) Theory of Nobel Prizewinning Economist Predicts Entrepreneurship vs Employment. [Online] Available from: http://www.paulzanepilzer.com/entrepreneurship_vs_employment

5. Pilzer, P. (2013b) Ron Coase, 1910 - 2013. [Online] Available from: http://www.paulzanepilzer.com/ron-coase.

6. Pilzer, P. (2011) Unemployment is Not an Economic Problem-It's an Education Problem. [Online] Available from: http://www.paulzanepilzer.com/unemployment-is-not-an-economic-problem-its-an-education-problem.

7. Pilzer, P. (2010) The Class of 2010 - What New Job Applicants Need Most. [Online] Available from: http://www.paulzanepilzer.com/the-class-of2010-what-new-job-applicants-need-most.

8. Pilzer, P. (2009b) Employment Update: Why Things are About to Get Much Worse. [Online] Available from: $\mathrm{http} / /$ www.paulzanepilzer.com/employment-update-why-things-are-about-to-get-much-worse.

9. Pilzer, P. (2006) Crisis or Opportunity - Your Business Magazine - July 2006. [Online] Available from: http://www.paulzanepilzer.com/ybcyberwize-htm. 